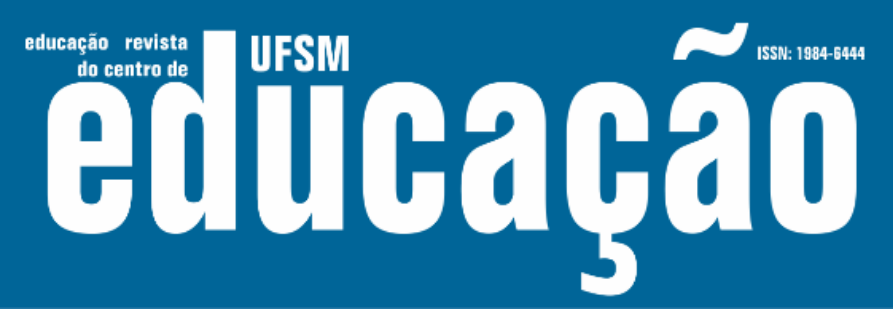

ISSN: 1984-6444 | http://dx.doi.org/10.5902/1984644435603

\title{
Participação da comunidade na autoavaliação institucional em universidades da Argentina, Brasil e Paraguai: os casos da UFFS, UNE, UNNE e UTFPR
}

\author{
Participation of the community in institutional self-evaluation in \\ universities of Argentina, Brazil and Paraguay: the cases of UFFS, UNE, \\ UNNE and UTFPR
}

Weslei Trevizan Amâncio

Assistente Social na Universidade Tecnológica Federal do Paraná, Londrina, Paraná, Brasil. wesleitamancio@gmail.com - https://orcid.org/0000-0002-8923-9434

Gustavo Biasoli Alves

Professor doutor na Universidade Estadual do Oeste do Paraná, Toledo, Paraná, Brasil. gbiasoli@uol.com.br - https://orcid.org/0000-0003-3788-9272

Recebido em 12 de novembro de 2018

Aprovado em 30 de outubro de 2019

Publicado em 15 de maio de 2020

\section{RESUMO}

A avaliação institucional nas universidades, e, dentro desse universo, a autoavaliação e a defesa da participação da comunidade nos processos, vêm se desenvolvendo com maior força nas últimas três décadas, tendo auferido importantes contornos e formas junto às políticas públicas destinadas à educação de nível superior. Neste sentido, analisamos neste artigo a participação da comunidade na autoavaliação institucional realizadas em universidades públicas da Argentina (UNNE), Brasil (UFFS, UTFPR) e Paraguai (UNE). O embasamento teórico se deu por meio de revisão da bibliografia especializada do tema; os recursos metodológicos utilizados são o estudo comparado, a pesquisa documental e a análise de conteúdo, com abordagens quantitativa e qualitativa. Destacamos a contradição entre os avanços constantes nas teorias, textos das normas e documentos institucionais, que defende e incentiva à participação da comunidade nos processos autoavaliativos institucional nas universidades, e, de forma diversa, o movimento operado pela política neoliberal, especialmente sobre as universidades públicas, uma vez que ao promover o modelo de gestão gerencialista e a concepção de avaliação objetivista em seu ambiente, valoriza a concentração dos espaços de decisão estratégicos e a instrumentalização da participação da comunidade, refletindo no seu enfraquecimento. Traços esses identificados nas análises dos dados e informações dos processos autoavaliativos institucionais, nas quatro universidades pesquisadas. Deste modo, apontamos que há muito a ser reavaliado, refletido e corrigido nos processos autoavaliativos estudados, 


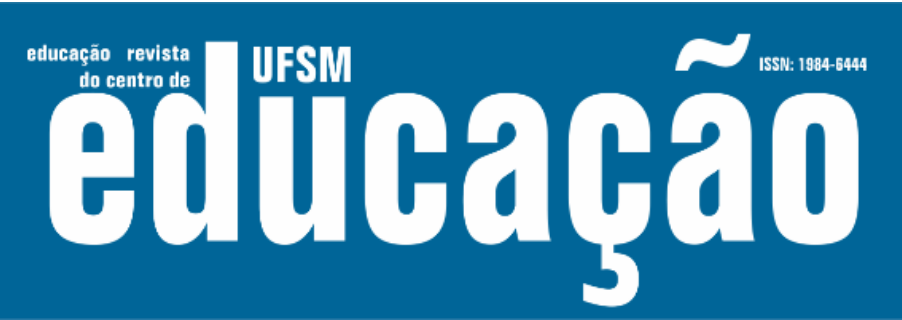

ISSN: 1984-6444 | http://dx.doi.org/10.5902/1984644435603

particularmente no que diz respeito a maior participação da comunidade na sua elaboração, planejamento, execução, ou seja, em seu efetivo envolvimento na construção do todo da ação avaliativa.

Palavras-chave: Autoavaliação institucional; Participação; Universidade.

\begin{abstract}
Institutional evaluation in universities, and within this universe, self-assessment and defense of community participation in the processes, have been developing with greater force in the last three decades, having gained important contours and forms with the public policies aimed at level education higher. In this sense, we analyze in this article the participation of the community in the institutional self-assessment carried out in public universities of Argentina (UNNE), Brazil (UFFS, UTFPR) and Paraguay (UNE). The theoretical basis was based on a review of the specialized bibliography of the theme; the methodological resources used are the comparative study, the documentary research and the content analysis, with quantitative and qualitative approaches. We highlight the contradiction between the constant advances in theories, texts of norms and institutional documents, which defends and encourages community participation in institutional self-assessment processes in universities, and, in a different way, the movement operated by neoliberal politics, especially on public universities, since in promoting the managerialist management model and the conception of objectivist evaluation in its environment, it values the concentration of the strategic decision spaces and the instrumentalization of community participation, reflecting in its weakening. These traits are identified in the analyzes of the data and information of the institutional self-assessment processes, in the four universities surveyed. In this way, we point out that there is much to be re-evaluated, reflected and corrected in the self-assessment processes studied, particularly with regard to the greater participation of the community in its elaboration, planning, execution, that is, in its effective involvement in the construction of the whole of the action evaluation.
\end{abstract}

Keywords: Institutional self-evaluation; Participation; University.

\title{
Introdução
}

O presente artigo tem como objetivo analisar a participação da comunidade na autoavaliação institucional realizadas na Universidade Federal da Fronteira Sul UFFS (Brasil), na Universidad Nacional del Este - UNE (Paraguai), na Universidad Nacional del Nordeste - UNNE (Argentina) e na Universidade Tecnológica Federal do Paraná - UTFPR (Brasil). A motivação e o interesse pela realização das avaliações nas universidades, constante na literatura e observada nas experiências da Argentina, Brasil e Paraguai, expressa-se pela preocupação em estabelecer uma melhor 


\section{Aitloabูão}

ISSN: 1984-6444 | http://dx.doi.org/10.5902/1984644435603

regulamentação e estruturação de sistemas e processos avaliativos, com o propósito de garantir uma referência de qualidade e instrumentalizar ações com vistas ao desenvolvimento das instituições.

Dentro desse quadro, destacamos a ênfase atribuída à participação da comunidade na autoavaliação institucional, defendida e igualmente compartilhada na teoria, normas e instrumentos de orientação para a sua realização. Desta forma, o envolvimento da comunidade nos processos autoavaliativos passa a ser tecido como ponto relevante e expresso em regra como um valor e formas asseguradoras da qualidade, transparência e democracia das ações avaliativas (BARREYRO; LAGORIA, 2010; MOROSINI, 1998).

Todavia, em que pese os avanços constantes na teoria, bem como nos textos das normas e documentos institucionais, que defende e incentiva a participação da comunidade nos processos autoavaliativos institucional nas universidades, de forma diversa, quando analisamos o movimento operado pela política neoliberal sobre as universidades públicas, observa-se uma contradição, uma vez que ao promover o modelo de gestão gerencialista e a concepção de avaliação objetivista em seu ambiente, valoriza a concentração dos espaços de decisão estratégicos e a instrumentalização da participação da comunidade, refletindo no seu enfraquecimento. Problemática essa que pretendemos avaliar neste artigo, mediante estudo comparado e análise nas instituições universitárias supracitadas.

Para tanto, na sequência apresentamos a metodologia em que se sustenta este trabalho de pesquisa; seguido de duas seções de desenvolvimento, em que abordamos: (i) o contexto, condições e intenções que estão envoltas à realização da avaliação em universidades; e (ii) os atores que se encontram presentes e ausentes na realização da autoavaliação institucional nas universidades pesquisadas. Em seguida, tecemos considerações finais, na qual apresentamos algumas reflexões e apontamentos com vistas a responder o problema da pesquisa e, respectivamente, contribuir com o tema estudado. 


\section{Aitloabูão}

ISSN: 1984-6444 | http://dx.doi.org/10.5902/1984644435603

\section{Metodologia}

Inicialmente, realizamos estudo exploratório de modo a selecionar as instituições de educação superior às quais incidiriam as pesquisas para a verificação da problemática levantada. Quanto às instituições brasileiras, os pesquisadores já tinham previamente em mente o interesse tanto pela UFFS quanto pela UTFPR, universidades públicas federais, que são submetidas às mesmas normas e regras de avaliação institucional.

No que diz respeito às universidades da Argentina, inicialmente, além da UNNE, selecionamos a Universidad Nacional de Misiones - UNAM, e no Paraguai, além da UNE, selecionamos a Universidad Nacional de Asunción - UNA, contudo, optamos, respectivamente, pelas primeiras instituições devido à existência da maior quantidade de documentação relativo aos processos de autoavaliação institucional.

Particularmente, cabe destacar que no plano da operacionalização e da busca da sistematização da avaliação institucional das e nas universidades da Argentina, Brasil e Paraguai, traço comum está na integração dos processos com a realização de avaliações externas, de responsabilidade de equipes compostas por notáveis na área de atuação, sendo a regra de credenciamento e realização por organismos estatais (ou exceção presente na Argentina, por instituições privadas com concessão estatal e competências para tal finalidade); e a autoavaliação institucional, realizadas e de responsabilidade de equipes, comissões, que são designadas para essa finalidade, instituídas pelas próprias universidades.

Nesse processo, porém, é importante destacar que há diferenças significativas no que diz respeito ao período, formato e operacionalidade na realização da autoavaliação e avaliação externa institucional nas universidades dos países.

Deste modo, enquanto no Brasil as universidades devem realizar a autoavaliação institucional anualmente, ao menos desde a vigência do Sistema Nacional de Avaliação da Educação Superior - SINAES (Lei n 10.861), no ano de 2004, independentemente da realização de avaliação institucional externa; na Argentina ela comumente ocorre apenas no ano anterior à realização da avaliação externa da instituição (a qual deve ser realizada a cada período de seis anos), servindo 


\section{T Tusm Edtoară}

ISSN: 1984-6444 | http://dx.doi.org/10.5902/1984644435603

de subsídio a essa última, conforme regulamentação disposta na Lei de Educação Superior (Lei n²4.521/1995). Já no Paraguai somente a partir do ano de 2015 que, com a estruturação "Mecanismo Experimental de Autoevaluación y Acreditación Institucional', se processa uma proposta de sistematização de avaliação das universidades do país, cujas primeiras autoavaliações institucionais, que também devem acontecer no período anterior à avaliação externa, iniciam de modo experimental em seis universidades do país ${ }^{1}$ (ARGENTINA, 1995; BRASIL, 2004a; PARAGUAY, 2015).

A opção por um estudo comparado se apresenta como oportuno para apreender o movimento de participação da comunidade na autoavaliação institucional no âmbito das universidades, tendo em vista a amplitude do campo de análise e estruturação de inferências de causas gerais que o método permite, aptas a explicar formação, estabilidade e mudança em instituições políticas, possibilitando a melhor compreensão do fenômeno estudado e dos processos que o cercam (SANTOS, 2012).

Desse modo, temos em perspectiva que a comparação possibilita, conforme pontuam Lichbach e Zuckerman (1997 apud PASQUARELLI, 2014, p. 11): "examinar um caso e revelar o que ele nos diz sobre um amplo conjunto de fenômenos políticos, ou para destacar as particularidades da política para ideias teóricas gerais".

Assim, o método comparado servirá como referência exploratória nos caminhos que se abrem no decorrer do processo de investigação, possibilitando que não haja um afastamento demasiado de um trabalho sistemático sobre as questões que orientam o presente trabalho. De toda forma, conforme apontado por Silva (2016), o que torna a sua utilização mais relevante é a capacidade de instituir uma pluralidade de perspectivas analíticas, de abordagens e metodologias conjuntas, indicando, inclusive, os limites que se colocam para a compreensão dos fatos ou fenômenos estudados, apresentando-se como um importante instrumento de conhecimento e de análise da realidade.

Destaca-se ainda, entre os recursos metodológicos utilizados, além da revisão da bibliografia especializada sobre o tema de pesquisa, a pesquisa documental e a 


\section{Aitloabูão}

ISSN: 1984-6444 | http://dx.doi.org/10.5902/1984644435603

análise de conteúdo (EVANGELISTA, 2012). No diz que respeito à pesquisa documental, em grande medida, se utilizará e tratará de "materiais que não receberam ainda um tratamento analítico, ou que ainda podem ser reelaboradas de acordo com os objetivos da pesquisa", condições em que exige um significativo empenho nas leituras e análises, onde percorremos um caminho desafiador e ao mesmo tempo rico para potenciais descobertas (GIL, 1994, p. 73).

A base conceitual e a técnica da análise dos dados utilizados correspondem à análise de conteúdo proposta por Bardin (2006), que, enquanto método que se faz pela prática, consiste em um conjunto de técnicas de análise das comunicações. Ao utilizar procedimentos sistemáticos e objetivos para a descrição dos conteúdos das mensagens, Chizzotti (2006, p. 98) considera que a análise de conteúdo possibilita "compreender criticamente o sentido das comunicações, seu conteúdo manifesto ou latente, as significações explícitas ou ocultas".

Deste modo, a análise de conteúdo se mostra importante, pois, conforme aponta Bardin (2006, p. 38), possibilita a inferência de conhecimentos relativos às condições de produção (ou eventualmente, de recepção) das mensagens, existente em diversas formas de documentação do material coletado (na maioria das vezes constituindo-se de material textual), inferências esta que se processam sobre indicadores, podendo ser quantitativo ou qualitativo. Neste sentido, a técnica permite ultrapassar as incertezas e enriquecer a leitura dos dados coletados (MOZZATO; GRZYBOVSKI, 2011).

Nesta esteira, conjunto à análise de conteúdo sobre os documentos e dados coletados, no processo de produção da pesquisa são aplicadas as abordagens qualitativas e quantitativas (MINAYO, 1994). Lakatos e Marconi (2011, p. 269) consideram que "no método quantitativo, os pesquisadores valem-se de amostras amplas e de informações numéricas, enquanto que no qualitativo as amostras são reduzidas, os dados são analisados em seu conteúdo psicossocial e os instrumentos de coleta não são estruturados".

Frente ao quadro apresentado pela proposta de pesquisa, vislumbra-se combinar as abordagens qualitativa e quantitativa nas análises dos documentos 


\section{Aitloabูão}

ISSN: 1984-6444 | http://dx.doi.org/10.5902/1984644435603

pesquisados, por compreender que essa associação propicia uma visão, ao mesmo tempo, abrangente, em razão dos dados quantitativos, e aprofundada, em virtude dos dados qualitativos (MINAYO, 1994). Possibilitando, assim, em conjunto com a técnica da análise de conteúdo realizar de modo satisfatório as análises e inferências propostas neste trabalho.

\section{Contexto, condições e intenções envoltas à realização da avaliação em universidades}

A partir de 1980, começa a ganhar força nos países centrais do capitalismo a política neoliberal de "Estado mínimo", em contraposição a do "Estado de Bem-Estar Social". Entre esses países, os governos que ganham destaque na aplicação dos preceitos da política neoliberal são, em princípio, Estados Unidos da América (EUA) e Inglaterra. As medidas desenvolvidas impactam fortemente as políticas sociais desses países, no conteúdo e na forma, já que uma de suas principais propostas e ações se voltam para a diminuição das instituições públicas e, em contrapartida, que os serviços sociais sejam ofertados e regulados pelo mercado (BARREYRO; LAGORIA, 2010).

De acordo com Souza Filho (2013), a derrocada do modelo de regulação social promovido pelo "Estado de Bem-Estar Social" ganha contornos já no início dos anos de 1970, com as seguidas crises econômicas e consequente redução da taxa de crescimento vivenciado inicialmente nos EUA, mas que, devido sua importância econômica e influência exercida sobre diversos países - estipulada via dependência -, vão se intensificando e reverberando mundialmente.

Nesse contexto, os países da América Latina vão experimentar radicais transformações, assumindo configurações particulares se considerarmos a condição comum dos países da região de capitalismo dependente, abrangendo uma enormidade de instituições públicas estatais, com destaque para a reconfiguração das universidades públicas. 


\section{Hsy Eutraţá}

ISSN: 1984-6444 | http://dx.doi.org/10.5902/1984644435603

Para Tello (2015), uma questão chave do neoliberalismo corresponde ao protagonismo que os organismos internacionais, especialmente o Fundo Monetário Internacional (FMI), Banco Mundial (BM) e Banco Interamericano de Desenvolvimento (BID), exercem sobre a agenda de políticas educacionais dos governos e respectivos países. O mecanismo desse protagonismo estabelece-se via concessão de empréstimos e financiamentos educacionais, possibilitados por esses organismos, os quais, em contrapartida, estipulam o atendimento de condicionalidades, que, na prática, a exemplo do que se experimenta na relação reformadora gerencial do Estado, traduzem-se em formas restritivas de se governar.

Nesse contexto, Jardim (2010) afirma que a proposição da política neoliberal para a educação, mediante os processos reformadores, perpassa no seu deslocamento do campo social e político para o campo do mercado, fazendo com que o aparato educacional funcione à sua semelhança e oriente-se pela busca do atendimento dos seus interesses.

Para Santiago et al. (2003, p. 87), em um quadro de sucessivas políticas governamentais que promovem um "mercado (ou quase-mercado) na educação superior" o gerencialismo emerge como recurso e princípio orientador de gestão. Em decorrência, numa relação complexa, mudanças significativas são processadas dentro das universidades - podendo, dentre outros, ser observadas na adoção de novas metáforas presentes nos discursos dos gestores -, com impactos nos modelos de governos. Nessa esteira, o gerencialismo aparece como um corolário das mudanças neoliberais perpetrada sobre as dimensões das universidades, ingressando os seus dispositivos organizacionais com ar de naturalidade.

Amaral (2009, p. 16) destaca que os modelos importados do mundo corporativo para a gestão das universidades se apresentam como substitutos do que entendem ser "o lento, ineficiente processo decisório da colegialidade acadêmica". Neste sentido, a inserção de agentes externos na administração das universidades se justifica como medida de criação de dispositivos que as tornem mais sensíveis e conectadas com as propostas do "mundo exterior". 


\section{Aitloabูão}

ISSN: 1984-6444 | http://dx.doi.org/10.5902/1984644435603

Nesse movimento, segundo Considine (2001, apud AMARAL, 2009, p. 23), torna-se primordial abarcar as universidades "por uma poderosa lógica de gestão de desempenho, centralização executiva e um novo código de governança corporativa", bem como designar representantes com bons currículos administrativos para a condução do projeto de transformação.

De acordo com Barreyro e Lagoria (2010), contribuem de forma decisiva para as transformações que perpassam a educação superior na América Latina, especialmente a partir da década de 1980, o movimento conhecido como segunda reforma universitária ${ }^{2}$, pela qual se presencia a expansão do sistema, necessária, mas com baixos investimentos públicos. Assim, mostra-se como consequência uma expansão do sistema, com a criação de uma grande quantidade de instituições de educação superior e consequente ampliação do acesso principalmente pela via privada, sendo ampla a liberalização do mercado e escassa a regulação.

Para Mancebo, Vale e Martins (2015, p. 33), ainda que, por um lado, a expansão da educação superior, vivenciada de forma intensa nos últimos vinte anos, possa ser percebida como positiva do ponto de vista de ampliação do acesso da população ao ensino superior, por outro lado, é preciso atentar-se para alguns efeitos negativos da forma em que se processa ${ }^{3}$, pois a "expansão se dá sob a influência direta de demandas mercadológicas, valendo-se dos interesses da burguesia desse setor de ampliar a valorização de seu capital com a venda de serviços educacionais".

Assim, com o fenômeno da diversificação via privatização das instituições de educação superior assiste-se ao surgimento de uma grande quantidade de problemas, com deficiências em sistemas e instituições de educação relacionada à qualidade da formação oferecida, aos formatos organizativos assumidos, à sustentabilidade da organização, colocando em conflito a necessidade de regulação frente à autonomia que gozam especialmente as instituições universitárias (LAMARRA, 2005).

Para Barreyro e Lagoria (2010, p. 9), nesse novo cenário da educação superior, público-privado, da América Latina, surge à figura do "Estado avaliador", estabelecendo políticas de avaliação com a finalidade de "regular a flexibilização do sistema". Para Silva (2009, p. 78 ) o surgimento do "Estado avaliador" tem como 


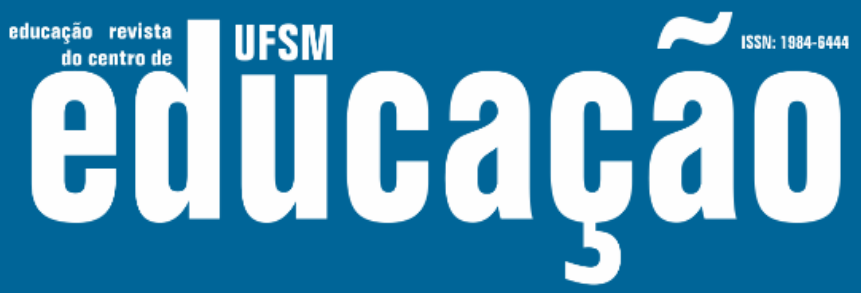

ISSN: 1984-6444 | http://dx.doi.org/10.5902/1984644435603

principal traço o fato do próprio Estado ter "deixado de produzir bens e, sobretudo, serviços, para concentrar na regulação dos processos produtivos".

Deste modo, vai sendo consolidada a tendência, compartilhada pelos países da região da América Latina, de expansão das instituições de educação superior e matrículas em vias privadas, a promulgação de leis voltadas para a regulação da educação superior e a criação de agências centrais para avaliar e acreditar as instituições universitárias e não universitárias (MOLLIS, 2008, p. 509).

São exemplos de normatização, mais recentemente: na Argentina, a Lei de Educação Superior ( $n^{\circ}$ 24.521/1995), que, dentre outras, prevê a criação da Comissão Nacional de Avaliação e Acreditação Universitária - CONEAU, e a Lei Nacional da Educação ( $n^{\circ}$ 26.206/2006); no Brasil, a Lei de Diretrizes e Bases da Educação Nacional - LDB (n 9.396/1996) e a Lei do Sistema Nacional de Avaliação da Educação Superior - SINAES ( $n^{\circ} 10.861 / 2004$ ), bem como a criação da Comissão Nacional da Avaliação da Educação Superior - CONAES, do Instituto Nacional de Estudos e Pesquisas Educacionais Anísio Teixeira - INEP, e da Comissão Própria de Avaliação - CPA, nas instituições de educação superior; e, no Paraguai, a Lei de Educação ( $n^{\circ} 1.264 / 1998$ ), a Lei da Educação Superior ( $n^{\circ} 4.995 / 2013$ ) e a Lei de criação da Agência Nacional de Avaliação e Acreditação da Educação Superior ANEAES ( $\left.n^{\circ} 2.072 / 2003\right)$.

Frente a esse quadro, de acordo com Leite (2005, p. 12), as avaliações aplicadas nas universidades são atreladas a "medidas que os governos colocam em prática para justificar controles de qualidade e de gastos públicos, focando sua atenção nos processos de liberalização da economia". Para Silva (2009, p. 41), a presença do "Estado avaliador" resultará no forte desenvolvimento de "avaliações externas, somativas, centradas nos produtos, implantando formas de "rankiamento", comparações e práticas competitivas, orientadas pelo e para o mercado".

Portanto, realizada em um campo de conflitos, onde aspectos técnicos e políticos da avaliação se relacionam, estando determinado para a busca de resultados interessados (DIAS SOBRINHO, 2004), o "Estado Avaliador" tem como marca relevante a adoção dos modelos avaliativos de concepção objetivista, sustentada por 


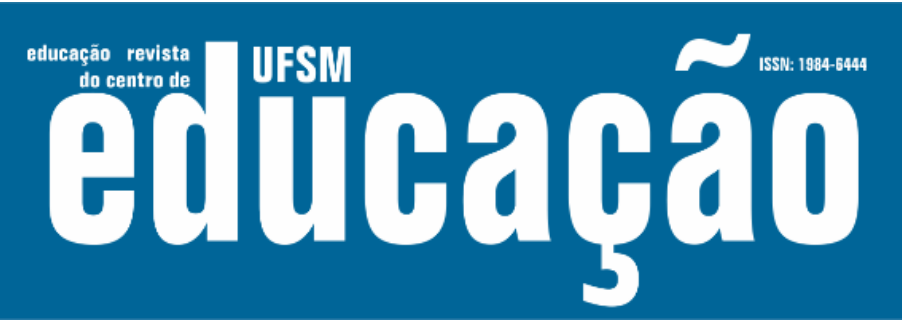

ISSN: 1984-6444 | http://dx.doi.org/10.5902/1984644435603

um grande aparato de avaliações externas sobre as instituições, com a estipulação de medidas quantitativas, com rígido controle dos resultados e foco nos produtos, promovendo práticas comparativas e competitivas (DA SILVA, 2009).

De acordo com Belloni (1999, p. 8) devemos compreender que a avaliação é mais do que um debate puramente técnico, pois está inserida e, portanto, precisa ser debatida considerando os aspectos éticos e políticos, especialmente quando se trata de instituições de educação superior. Neste sentido, a avaliação deve levar em conta a articulação entre meios e fins a que se destina a educação e considerar que "a avaliação é uma atividade que se caracteriza por traduzir um compromisso de ordem filosófica, social e política com a educação".

Ocorre, porém, que os modelos avaliativos de corte objetivista, levados a cabo em larga escala pelas agências governamentais, permeiam as instituições universitárias e se expressam não apenas no uso dos instrumentos da avaliação, mas também na definição de qualidade a qual se almeja. Essa qualidade, como destaca Pfeifer (2012), tem se colocado muito mais voltada para "Qualidade Eficiência", com os requisitos de produtividade, rentabilidade e competitividade, que são próprios da racionalidade econômica, do que para a "Qualidade Social”, a qual destina à educação superior o processo fundamental de construção democrática e cidadã.

Assim, considerando que as políticas neoliberais vêm consubstanciando a valorização das ferramentas gerenciais na gestão das universidades e que os processos avaliativos de concepção objetivista - circunscritos no estabelecimento da eficácia segundo os modelos empresariais, permeados por forte centralização e concentração do poder decisório - estão presentes, os valores neoliberais se apresentam com forte tendência sobre os sentidos e objetivos do processo avaliativo nas universidades (DIAS SOBRINHO, 2004).

Atentos a esses fatores, é extremamente importante que qualquer análise que verse sobre a universidade deve partir da compreensão de que se trata de uma instituição complexa, constituída por grande diversidade, com tamanha grandeza que faz com que cada uma seja singular na sua complexa diversidade. Nesse sentido, invariavelmente, a conformação de uma universidade envolve processos sociais, 


\section{A Wry efitoaţá}

ISSN: 1984-6444 | http://dx.doi.org/10.5902/1984644435603

grupos de interesses, "relações de ensino e aprendizagem; forma recursos humanos; produz e dissemina conhecimentos e presta diferentes serviços à comunidade" (PINTO; HEINZEN; MELO, 2005, p. 112).

Nessa perspectiva, Dias Sobrinho (2005) destaca que, enquanto prática interessada, um processo avaliativo permite produzir resultados significativos na medida em que trabalha os nexos entre uma dada realidade e seu contexto, e, ademais, como condição essencial, possibilite a articulação entre o contexto identificado e horizontes mais amplos. Assim, diante de um cenário de fragmentação das partes, comumente encontrado em instituições de educação superior, a avaliação deve buscar estabelecer os nexos das partes com o todo.

Como atitude heurística, a avaliação busca compreender, por meio de aproximações, a totalidade de uma instituição. Não que o todo institucional vá se desvelar com toda a clareza e em plenitude àqueles que participam da avaliação. O que se espera é produzir alguns conhecimentos e julgamentos sobre as diversas dimensões - corpo social, ensino, pesquisa, extensão, infraestrurura, gestão, relações com a sociedade, projetos e realizações, etc. -, não isoladamente, mas articuladamente. (DIAS SOBRINHO, 2005, p. 33)

Nessa esteira, Polidori, Fonseca e Larrosa (2012, p. 336), ao analisarem as condições encontradas na maior parte das instituições de educação superior, ressaltam dificuldades presentes ao trabalhar com análises que buscam a agregação dos elementos da instituição. As dificuldades, em grande parte, se relacionam a própria complexidade envolta ao tema avaliação, ao contexto em que está inserida a instituição e a realidade da educação superior do país. De toda forma, enfatizam que é preciso compreender que, por menor que seja, cada instituição "possui sua complexidade e a sua diversidade que devem ser respeitadas, mas, acima de tudo, devem ser consideradas e enfrentadas para que seja possível desenvolver um processo avaliativo que realmente envolva todos e que busque compreender o meio". 


\section{Aitloabูão}

ISSN: 1984-6444 | http://dx.doi.org/10.5902/1984644435603

\section{Atores presentes e ausentes na realização da autoavaliação institucional nas universidades pesquisadas}

Pinto, Heinzen e Melo (2005, p.113) apontam como elemento central na análise da avaliação institucional à participação da comunidade no processo avaliativo, de modo que o envolvimento dos atores, interno e externo à instituição, contribui significativamente na definição do próprio sentido da avaliação e "o que e como avaliar passa a ser discutido em função daquilo que pode ser tido como o mais importante para a visibilidade da instituição".

Nesse sentido, a participação dos agentes certamente estabelece influência sobre as finalidades a que se aplica a avaliação, podendo assumir uma perspectiva de "avaliação emancipatório", pela qual, em um contexto universitário, se estabelece o compromisso de transformação para a melhoria acadêmica, ampliação e aprofundamento do conhecimento da instituição, fortalecimento da responsabilidade social; ou, ao contrário, assumir uma perspectiva de "avaliação regulatória", pela qual importa a realização do controle e fiscalização, por parte do Estado e agências reguladoras, aferindo e demonstrando a capacidade competitiva da instituição (PINTO; HEINZEN; MELO, 2005).

Deste modo, dentro dos mecanismos mobilizados para justificação e legitimação da estruturação das agências e sistemas avaliativos e de regulação das instituições de educação superior, particularmente nos países latino-americanos, observa-se a constante do envolvimento da comunidade nos processos avaliativos, aparecendo como ponto relevante nas normativas da Argentina, Brasil e Paraguai, expresso como uma das medidas garantidoras da qualidade (BARREYRO; LAGORIA, 2010; MOROSINI, 1998).

Assim, quanto ao cumprimento dos objetivos de contribuir com a melhoria da qualidade na realização da autoavaliação institucional, na Argentina, a CONEAU aponta, dentre outros, a necessidade de promover a participação dos integrantes da comunidade universitária, no Brasil, a CONAES apresenta que tal objetivo só é possível com a participação efetiva de toda a comunidade interna e com a contribuição de atores externos do entorno da instituição e, no Paraguai, a ANEAES destaca que 


\section{Aitloabูão}

ISSN: 1984-6444 | http://dx.doi.org/10.5902/1984644435603

o melhoramento da universidade depende de um modelo avaliativo na instituição que proceda de forma reflexiva e participativa (ARGENTINA, 2011; BRASIL, 2004c; PARAGUAY, 2014).

Diante desses entendimentos compartilhados, nas teorias e nas normas, a seguir apresentamos, em um primeiro momento, considerações sobre os atores os quais recaem a competência e a responsabilidade pela operacionalização da autoavaliação institucional nas universidades pesquisadas e, num segundo momento, já que os processos são realizados com essa divisão, os atores que são chamados para participar da autoavaliação, com destaque para os procedimentos e instrumentos adotados.

Conjuntamente, propõe-se uma análise das formas de operacionalização em que se desenvolvem os processos autoavaliativos nas instituições e algumas inferências acerca da correspondência ou não correspondência entre as teorias e normativas no que diz respeito ao envolvimento e a participação da comunidade na autoavaliação institucional diante das práticas institucionais que são levadas a cabo.

Nas instituições brasileiras, por força da Lei do SINAES compete à CPA a condução dos processos internos de avaliação da instituição, bem como pela sua sistematização (BRASIL, 2004b). Assim, na UFFS existe uma CPA, centralizada na Reitoria da instituição, sendo composta por dois representantes dos docentes e, respectivamente, um representante dos técnico-administrativos, estudantes e da sociedade civil; e mais uma subcomissão em cada um dos seus campi, compostas por um de cada representante dos docentes, técnico-administrativos, estudantes e da sociedade civil, sendo que todos os membros devem ser eleitos (UFFS, 2012a).

Na UTFPR, a CPA fica centralizada na Reitoria da instituição e conta com núcleos localizados nos demais campi que auxiliam em suas atividades. Integram os núcleos servidores da instituição designados pela Direção-Geral, já a CPA é composta por três representantes docentes, dois representantes dos técnico-administrativos, dois representantes dos estudantes e dois representantes da sociedade civil. Os membros docentes e técnico-administrativos da CPA são indicados pela Reitoria da instituição e 


\section{Aitloabูão}

ISSN: 1984-6444 | http://dx.doi.org/10.5902/1984644435603

os demais membros, pelas respectivas entidades representativas, e a presidência da comissão deve ser exercida por um dos membros docentes (UTFPR, 2009).

$\mathrm{Na}$ UNNE, o processo de autoavaliação institucional é conduzido sobre a responsabilidade da Comissão Central de Autoavaliação, composta por membros docentes e que tenham realizado o curso de "Pós-Graduação de Avaliação Institucional" de cada uma das unidades acadêmicas da instituição, e as Comissões de Avaliação das Faculdades e Institutos. Ambas têm seus membros indicados pelos dirigentes da instituição (UNNE, 2008). Na UNE, o processo de autoavaliação institucional é de competência e responsabilidade do Comitê de Autoavaliação, vinculada à Direção Geral Acadêmica da Reitoria, cujos membros docentes são indicados pelo Reitor, e contam com o auxílio de comitês locais vinculados a cada uma das unidades acadêmicas da instituição (UNE, 2016).

No que diz respeito à efetivação da participação da comunidade na autoavaliação institucional há particularidades em cada uma das instituições as quais competem ser destacadas.

$\mathrm{Na}$ UNNE, no último processo realizado entre os anos de 2005 e 2006, do qual foi publicado o Informe Final de Autoavaliação Institucional no ano de 2008, consta que fora realizadas entrevistas com ocupantes de cargos e responsáveis por funções administrativas na universidade. Além dessas entrevistas, realizaram entrevistas com pessoal da comunidade interna (docente, estudantes e funcionários) e com pessoal da comunidade externa. Ao todo, contabilizam 2.831 mil participantes, dos quais 514 docentes, 1.423 mil estudantes e 173 funcionários, além de 729 pessoas da comunidade externa. As questões que foram aplicadas não constam no Informe Final, contudo, são apresentados enquanto resultado considerações acerca de seis indicadores institucionais estruturados pela Comissão Central de Autoavaliação (UNNE, 2008).

Na UFFS, em todos os anos pesquisados, entre 2012 e 2017, foram realizados processos autoavaliativos. Segundo consta, a participação da comunidade se deu por meio de pesquisa de satisfação acerca das dez dimensões do SINAES, onde 


\section{Aitloabูão}

ISSN: 1984-6444 | http://dx.doi.org/10.5902/1984644435603

membros dos três seguimentos da comunidade interna foram convidados a responder questionário com questões a elas relacionadas.

Contudo, as consultas foram realizadas junto à comunidade pela CPA na UFFS apenas nas autoavaliações dos anos de 2012, 2016 e 2017, conforme verificado nos documentos institucionais. No ano de 2012, participaram respondendo o questionário 212 estudantes, 207 docentes e 148 técnico-administrativos em educação, que correspondem a $3 \%$, 38\% e $27 \%$ dos seus respectivos seguimentos (UFFS, 2013); no ano de 2016, participaram respondendo o questionário 431 estudantes, 165 docentes e 116 técnico-administrativos em educação, que correspondem, respectivamente, a $5,5 \%, 22 \%$ e $18 \%$ dos seus seguimentos (UFFS, 2017); e no ano de 2017, participaram da autoavaliação institucional respondendo ao questionário 207 estudantes, 86 docentes e 77 técnico-administrativos em educação, que correspondendo a 2,5\%, 11\% e 11\% dos seus respectivos seguimentos (UFFS, 2018).

$\mathrm{Na}$ UTFPR, de outra forma, ocorrem distintos processos avaliativos sobre temáticas determinadas, que estão voltadas para públicos específicos, como a do "Docente pelo Discente", em que o estudante avalia o desempenho e satisfação que tem dos seus professores; a "Avaliação do Servidor", na qual os servidores são avaliados pelas suas respectivas chefias; a "Avaliação Externa", em que o público usuário dos distintos serviços da universidade avalia o atendimento prestado pelos servidores de determinado setor; e a "Avaliação do Clima Organizacional”, em que apenas docentes e técnico-administrativos avaliam dez categorias de analises voltadas à gestão da universidade. Nesse sentido, é considerada a participação da comunidade na autoavaliação institucional mediante a realização desses distintos processos avaliativos (UTFPR, 2017b).

$\mathrm{Na}$ UNE, a autoavaliação institucional possibilita a participação e colhe as manifestações apenas dos ocupantes de cargos e funções administrativas nas distintas unidades acadêmicas da universidade. Não há, portanto, a realização de consulta direta à comunidade externa, e no caso da interna, apenas aos ocupantes de algum dos cargos ou funções mencionadas. O instrumento utilizado consiste na realização de oficinas com essa parcela da comunidade universitária, que versaram 


\section{Aitloabูão}

ISSN: 1984-6444 | http://dx.doi.org/10.5902/1984644435603

sobre temas voltados para diagnosticar o atendimento das dimensões e componentes previstos no "Mecanismo de Autoavaliação" proposto pela ANEAES (UNE, 2016).

Assim, quanto à composição dos órgãos e instâncias institucional as quais recaem a competência e a responsabilidade pela operacionalização da autoavaliação institucional nas universidades pesquisadas, ainda que nas instituições brasileiras, por expressa previsão legal (art. 11 da lei $n^{\circ} .10 .861$ - SINAES), a CPA tanto da UFFS quanto da UTFPR contam com representantes dos três seguimentos da comunidade universitária e da comunidade externa em sua composição, na prática essa composição não tem refletido em maior envolvimento da comunidade na elaboração das dimensões e respectivas abrangências, objetivos, bem como dos procedimentos e instrumentos adotados nos processos autoavaliativo institucional.

Ainda que previsto nos Projetos de Avaliação Institucional das CPA's, em ambas as universidades o envolvimento da comunidade em todo o processo avaliativo, a definição acerca desses fatores e da operacionalização da autoavaliação institucional tem ficado restrito às próprias comissões, sendo a comunidade chamada a participar em momento posterior, respondendo a pesquisas com questões em sua maioria previamente definidas e com formatos fechados.

Na UNNE e na UNE, da mesma forma que nas instituições brasileiras, a comunidade universitária e externa às instituições não têm sido chamadas para participar na construção do processo autoavaliativo como um todo, ficando restritos a, respectivamente, responder entrevistas e participar de oficinas temáticas. Contudo, diferentemente das instituições brasileiras, não há nem mesmo a garantia da participação de representantes dos três seguimentos pertencentes à comunidade universitária na sua composição, tão pouco da comunidade externa. Seus membros são indicados pelos respectivos Reitores e dirigentes institucionais, conforme for o caso.

Assim, de acordo com o observado, nas quatro universidades pesquisadas há em comum na autoavaliação institucional que as definições do processo ficam restrito a determinados órgãos e instâncias, espaços com recortes bem definidos e composta por poucos atores da instituição, mas as quais se incumbem a realizar toda a operacionalização da autoavaliação institucional. A comunidade, porém, vem a ser 


\section{Aitloabูão}

ISSN: 1984-6444 | http://dx.doi.org/10.5902/1984644435603

chamada a participar apenas posteriormente, mediante a interação com instrumentos avaliativos de formatos definidos previamente e conformações específicas.

No que diz respeito ao momento e à forma que ocorre a participação da comunidade na autoavaliação institucional, conforme descrito, existem singularidades e diferenças que são significativas, tanto nos procedimentos quanto nos instrumentos adotados.

Na UFFS e na UNNE, os procedimentos e instrumentos adotados, ainda que em um único formato, mediante, respectivamente, a pesquisa de satisfação e entrevista, possibilitam a participação da comunidade na autoavaliação institucional em perspectiva mais global, de modo que os instrumentos aplicados ensejam a avaliação de distintas dimensões da instituição em um único processo, com a diferença que na primeira instituição participaram apenas membros da comunidade interna e na segunda, membros da comunidade interna e externa à universidade.

Na UTFPR, os procedimentos e instrumentos de avaliação são fragmentados e a participação no processo avaliativo se dá de forma parcelada, não sendo os itens avaliados pela comunidade interna diretamente relacionadas às dimensões do SINAES - diferentemente de como acontece na UFFS onde as pesquisas apresentam questões relacionando as respectivas dimensões do SINAES. Posteriormente, a própria CPA da UTFPR realiza a associação dos distintos itens avaliados nos processos avaliativos ao que entende corresponder às referidas dimensões.

$\mathrm{Na}$ UNE, ainda que a autoavaliação realizada verse sobre as dimensões e respectivos componentes constantes no "Mecanismo Experimental de Autoevaluación y Acreditación Institucional", estipulado pela ANEAES, à participação no processo se restringe a atores da comunidade interna e, dentre estes, apenas os ocupantes de cargos e funções na administração da instituição, que realizam as suas contribuições em oficinas temáticas.

Diante desse quadro que se apresenta é oportuno pensar na concepção gerencialista de gestão e a sua primazia por centralização dos espaços de decisão estratégicos da instituição, revestindo-os de aparatos que ou inviabilizam a participação da sociedade civil ou, quando permite, descentraliza apenas 


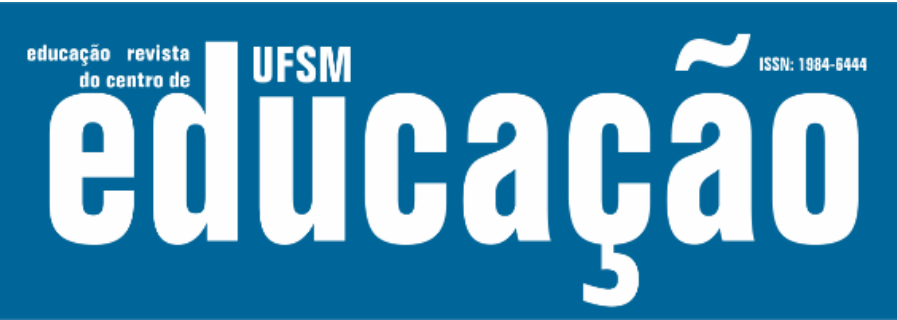

ISSN: 1984-6444 | http://dx.doi.org/10.5902/1984644435603

responsabilidades e promove uma participação instrumental, parcial, a qual busca-se resultados somatórios, com pouca ou nenhuma possibilidade de transformação dos agentes e processos (DAGNINO, 2004; NOGUEIRA, 2011; PAULA, 2005).

Nesse sentido, compete destacar que ainda que com uma operacionalização que contam com procedimentos e instrumentos que possibilitam a participação da comunidade na autoavaliação institucional de forma mais significativa, quando comparada, por exemplo, com a UNE e a UTFPR, tanto na UFFS quanto na UNNE observam-se limites na adoção de um único formato de consulta. Pois, conforme enfatizamos, em sua maioria remetem a questões fechadas, as quais são previamente definidas e formuladas pelos respectivos órgãos e instâncias institucionais, que não possibilitam a participação da comunidade em sua elaboração e possuem recortes muito definidos e composição restrita. Posteriormente, em comum, operam movimentos semelhantes de transformação das respostas colhidas em índices institucionais.

No caso da fragmentação dos processos avaliativos identificados na UTFPR, em particular, ainda que a CPA possa desenvolver uma tentativa de junção e em uma perspectiva de globalidade realizar um diagnóstico, preocupa o fato da participação da comunidade se dar de forma parcelada. Pois, esse modelo pode prejudicar a análise global que requer a avaliação feita pelo ator institucional, já que o instrumento Ihe permite avaliar apenas uma determinada perspectiva institucional e, de outro modo, esse mesmo ator pode participar de um e deixar (ou ser impossibilitado) de participar do outro, prejudicando a leitura que a instituição consegue sobre os atores desse processo.

De outro modo, em que pese os processos que permitem à consulta direta da comunidade universitária sobre os temas da autoavaliação institucional na UFFS, no Relatório de Autoavaliação Institucional do ano de 2017, considerando que grande parte das informações e mesmo os resultados das pesquisas apresentadas nos relatórios anteriores estão se repetindo (encontrando praticamente inalteradas), somado ao fato do registro da crescente redução do número de participantes respondendo aos questionários, a CPA destaca que os resultados apontados nos 


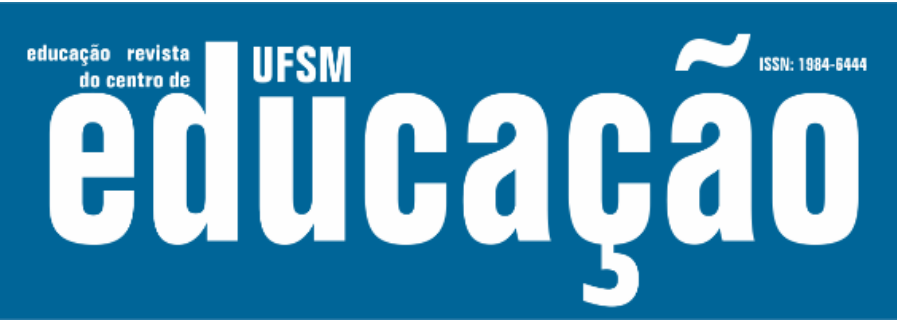

ISSN: 1984-6444 | http://dx.doi.org/10.5902/1984644435603

relatórios devem ser "conhecidos e utilizados pelos diferentes setores e segmentos da UFFS, de modo a obter melhorias perceptíveis, especialmente em aspectos que mereçam maior atenção, com o mínimo de recursos econômicos e humanos necessários" (UFFS, 2018, pp. 169-170).

Na UNNE, o Informe Final de Avaliação Externa, realizada pela CONEAU e apresentado no ano de 2011, tece considerações diversas acerca da autoavaliação realizada, com destaque presentes nas recomendações (a despeito dos diagnósticos apresentados nos instrumentos de autoavaliação) sobre a necessidade de "manejo de información contextual que sustente los diagnósticos y las propuestas", a realização de apresentação de avaliação dos impactos dos programas apresentados e direcionamento das ações para a resolução mais específicas das problemáticas (ARGENTINA, 2011, p. 33).

Assim, se considerarmos que entre vários sentidos, conforme defendido por Dias Sobrinho (2005, p. 33), a avaliação participativa também mostra-se como um importante instrumento de articulação, pois prima por ser um processo relacional entre "o corpo social, as diversas funções, dimensões e estruturas institucionais, os meios e os fins, os instrumentos e os momentos", como podemos pensar as propostas autoavaliativas produzidas em cada uma das universidades pesquisadas, especialmente no que diz respeito à participação e envolvimento da comunidade? Qual a parcela de contribuição da comunidade na realização dos processos autoavaliativos institucional na UFFS, UNE, UNNE e UTFPR?

Frente a esse contexto, qual a importância que assumem os processos autoavaliativos institucional desenvolvidos nas referidas universidades se pensarmos que, de acordo com Dias Sobrinho (2005), a avaliação participativa, com o envolvimento dos agentes membros da instituição educativa, é de fundamental importância para o fortalecimento institucional, de modo que contribui para a democratização dos processos, dinamizando a educação e conhecimentos que só podem ser adquiridos coletivamente.

Em consequência, quais possibilidades estão presentes nos processos autoavaliativo nas universidades pesquisadas, já que, conforme destacam Pinto, 


\section{N Fitlaabat}

ISSN: 1984-6444 | http://dx.doi.org/10.5902/1984644435603

Heinzen e Melo (2005, p. 116), em um processo que conste uma gestão participativa e integradora a proposta avaliativa poder ser construídas de diferentes maneiras, não sendo engessado e, com isso, possibilitando permanentes revisões nas estratégias e metas em todas as áreas da organização.

Consideramos que as questões acimas elencadas, frente aos quadros institucionais apresentados, são de extrema importância para auxiliar na compreensão do processo avaliativo e da própria instituição de educação superior, de modo que à medida da relevância constitutiva da avaliação (enquanto importante instrumento de conhecimento da realidade institucional e de autentica organizadora das suas potencialidades) está diretamente relacionado à amplitude da democracia e participação da comunidade universitária empregada em seu processo de realização. Pois, dessa compreensão, somado ao sentido de integração pelo qual se realiza a avaliação, depende a construção de "ações pertinentes a levar a instituição educativa a exercer, com mais qualidade e eficácia, as suas funções científicas e sociais" (DIAS SOBRINHO, 2005, p. 35).

Portanto, temos acordo com Leite (2005, p. 10), quando destaca que uma universidade consegue atingir patamares elevados de qualidade mediante a realização de uma avaliação institucional que proporcione o diagnóstico de uma instituição viva. Conforme esclarece a autora:

\footnotetext{
Refiro-me a uma avaliação inovadora realizada por dentro, participativa e democrática que conte com o envolvimento das comunidades interna e externa. A avaliação, sob este ponto de vista e concepção, contribui para definir ponto fortes e fracos, de cada unidade, curso, departamento, núcleo ou grupo de trabalho e, com isto, entender o que os faz serem diferentes, ou seja, onde está a riqueza da diferença, sua qualidade no nível micro e macroinstitucional. Ao mesmo tempo, ao olhar para os lados, ao buscar elementos ao entendimento, faz sair de dentro dos limites e amarras institucionais, destacando o valor do conhecimento universal ao lado da construção, por dentro da ação, de um processo democrático.
}

Dessa forma, é esperado que o emprego de uma avaliação em bases mais participativa possibilite um diagnóstico mais fidedigno das experiências práticas cotidianas e, consoante a uma proposta formativa, permita apontar medidas corretivas 


\section{Aitloabูão}

ISSN: 1984-6444 | http://dx.doi.org/10.5902/1984644435603

para a melhoria no desenvolvimento da instituição como um todo, de modo mais completo, uma vez que abarca maior gama das dimensões e aspectos relacionais existentes (DIAS SOBRINHO, 2005). Nessa perspectiva, Dias Sobrinho (2000, p. 77) defende que é imprescindível que a avaliação busque intervir qualitativamente nas dimensões institucional e, para tanto, mostra-se necessário ultrapassar o domínio tecnicista e envolver o "sujeito coletivo, a comunidade intersubjetiva dos atores universitários" no processo avaliativo.

Pois, a avaliação formativa, destoando das perspectivas avaliativas produtoras de classificação e competição, apresenta-se sustentada na construção de resultados que possibilitam enxergar demandas potenciais, permitindo correções e melhorias necessárias para o desenvolvimento institucional. Desse modo, ao levar em conta no processo avaliativo o sujeito da avaliação, incentivando a participação, o debate e a reflexão sobre o objeto avaliado (articulados em etapas e instrumentos integrados e complementares, resultando em relatórios e pareceres indicativos), possibilita-se a produção de um rico autorretrato institucional. Esse processo avaliativo contribui de forma mais significativa para "a resignificação, a reconstrução e a transformação dos processos educativos e dos próprios sujeitos" (PFEIFER, 2012, p. 359).

Esse movimento contribuirá, em seu conteúdo e forma, com o desenvolvimento de uma atividade avaliativa fortalecida democraticamente e, por consequência, de promoção de uma cultura avaliativa em que o engajamento da comunidade estará presente na construção e consolidação do processo autoavaliativo, especialmente refletidas em ações de cobrança por tomada de decisões com vistas ao atendimento dos resultados expressos nas avaliações construídas (ANDRIOLA; SOUZA, 2010; KÖNIG, 2007).

Assim, concordamos com Dias Sobrinho (2005) ao afirmar que a avaliação se constitui em um espaço legítimo de construção de críticas à medida que se mostra integradora da comunidade em sua produção. Sendo realizada como um espaço de formação no qual as dimensões técnico-científicas e ético-políticas estão incluídas, e tomando em conta a definição formativa do processo avaliativo, o seu sentido, mais do que um instrumento operacional de medição, constatação, verificação e checagem, 


\section{Aitloabูão}

ISSN: 1984-6444 | http://dx.doi.org/10.5902/1984644435603

passa a ser promoção de interrogação e de construção de respostas coletivas, ainda que não definitivas.

\section{Considerações finais}

Pelo cenário mostrado nos dados e informações, levantadas e analisadas, acreditamos que há muito a ser reavaliado, refletido e especialmente corrigido e desenvolvido nos processos autoavaliativos, sem exceção, de todas as quatro universidades pesquisadas (UFFS, UNE, UNNE e UTFPR). Particularmente, no que diz respeito à participação e envolvimento da comunidade na sua elaboração, planejamento, execução, ou seja, na construção da ação avaliativa em seu todo, já que, conforme identificado, muitos atores da instituição estão ausentes da operacionalização da autoavaliação institucional, em seu todo, e quando presentes, devido aos instrumentos e procedimentos adotados, participam com atuação limitada e, portanto, aquém das possibilidades realizadoras e transformadoras que pode significar um processo avaliativo.

Deste modo, acreditamos que, em maior intensidade na UNE e na UTFPR e em menor, na UFFS e UNNE, há um ciclo presente nos processos autoavaliativos, no qual a participação excessivamente instrumentalizada, direcionada e restrita, seguida da baixa participação da comunidade, não permite que as demandas essenciais apareçam a contento, acarretando em um diagnóstico superficial da realidade e dinâmica institucional. Em consequência, a não identificação das demandas presentes na instituição e o seu não atendimento (ou atendidas de modo insatisfatório), leva a uma descrença dos atores institucional no processo, que consubstancia em desestímulo à participação da comunidade e, deste modo, coloca em xeque a avaliação enquanto instrumento com potencial de transformação, bem como dificulta à promoção de uma cultura avaliativa com relevância institucional e social, nos termos cunhados por König (2007).

Nesse contexto, entendemos como oportuno problematizar os sentidos dos processos autoavaliativos institucionais circunscritos às universidades pesquisadas, 


\section{Aitloabูão}

ISSN: 1984-6444 | http://dx.doi.org/10.5902/1984644435603

com a promoção do debate acerca da elaboração, estruturação e intensificação de processos participativos, pelo qual o guia seja, em uma perspectiva de avaliação formativa e emancipatório, o aprofundamento do conhecimento da instituição, o compromisso de transformação com vista à melhoria acadêmico-científica e o fortalecimento da responsabilidade e do compromisso ético, democrático e social da universidade.

Compreendemos que a avaliação, e em especial a autoavaliação que realmente se proponha a ser em uma perspectiva participativa, deve primar pela participação integradora da comunidade, com o envolvimento dos seus atores na operacionalização e estruturando procedimentos e instrumentos que permitam a maior e mais efetiva participação da comunidade, possibilitando, assim, a construção de uma avaliação que considera elementos vivos da dinâmica institucional (LEITE, 2005).

Dessa forma, ressaltamos que competem aos gestores e dirigentes da instituição definir e realizar de forma ampla e em conjunto com os membros dos órgãos e instâncias as quais recaem as responsabilidades pela autoavaliação institucional e com a comunidade, interna e externa à universidade, as dimensões e abrangência do que estará sendo avaliado. Nesse processo, deve se estabelecer de forma clara a importância da participação dos atores institucionais, e as estratégias que serão lançadas para tanto, o objetivo da avaliação, os valores que estão consubstanciados na avaliação que será desenvolvida, em suma, destacando as razões e as circunstâncias diversas que fazem com que se tenha a necessidade (e a importância) de avaliar.

Contudo, é fundamental que esse processo seja organizado em uma perspectiva de avaliação participativa, a qual primando pela participação da comunidade possibilite os meios pelos quais se consolide a consumação de uma avaliação que considera elementos vivos da dinâmica institucional. Pois, consoante a uma proposta formativa, o seu emprego possibilita um diagnóstico mais fidedigno das experiências práticas cotidianas e, consequentemente, permite apontar medidas corretivas para a melhoria no desenvolvimento da instituição como um todo, de modo 


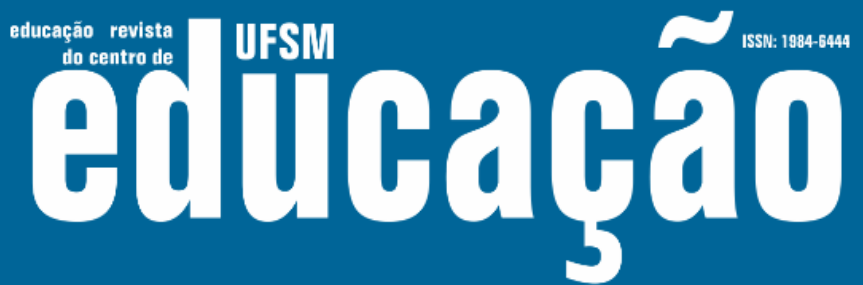

ISSN: 1984-6444 | http://dx.doi.org/10.5902/1984644435603

mais completo, uma vez que abarca maior gama das dimensões e aspectos relacionais existentes.

Entendemos que, ainda que tenha pela frente um grande e árduo caminho, onde enfrenta a resistência de um forte sistema político e econômico que molda barreiras locais, materiais e culturais, a avaliação participativa, em essência, busca promover o fortalecimento institucional, contribuindo para a democratização dos processos e permitindo a erudição de uma compreensão acerca da qualidade social da instituição, em um movimento contínuo que conecta e aproxima à universidade dos anseios e necessidades da comunidade a qual pertence. Contribuindo, com esse movimento, com a aproximação, envolvimento e participação da comunidade na própria constituição da universidade.

\section{Referências}

ANDRIOLA, Wagner Bandeira; SOUZA, Laura Alvez de. Representações sociais dos gestores e técnicos das unidades acadêmicas da UFC acerca da autoavaliação institucional. Revista Avaliação. Campinas: SP, v. 15, n. 2, p. 45-72, 2010. Disponível em: http://www.scielo.br/scielo.php?pid=S141440772010000200003\&script=sci_abstract\&tIng=pt. Acesso em: 04 out. 2018.

AMARAL, Alberto. Avaliação e qualidade do ensino Superior: as muitas racionalidades da qualidade. In: LEITE, D. (Org.). Avaliação participativa e qualidade: os atores locais em foco. Porto Alegre: Sulina, 2009. p. 11-32.

ARGENTINA. Comisión Nacional de Evaluación y Acreditación Universitária CONEAU. Informe de evaluación externa: universidad nacional del nordeste. 2011. Buenos Aires, Argentina: CONEAU, 2011. Disponível em:

http://www.coneau.edu.ar/archivos/libros_evaluacion_externa/EENordeste.pdf. Acesso em: 07 jun. 2018.

ARGENTINA. Ley de Educación Superior, n. 24.521; sancionada en 20 de julio de 1995; promulga parcialmente en agosto 07 de 1995. Boletín Oficial de la Republica de la Argentina, 10 ago. 1995. Número: 28.204, página 1. Disponível em: http://servicios.infoleg.gob.ar/infoleg Internet/verNorma.do?id=25394. Acesso em: Acesso em: 03 de ago. 2017.

BARDIN, Laurence. Análise de Conteúdo. Lisboa, Portugal: Edições 70, LDA, 2006. 


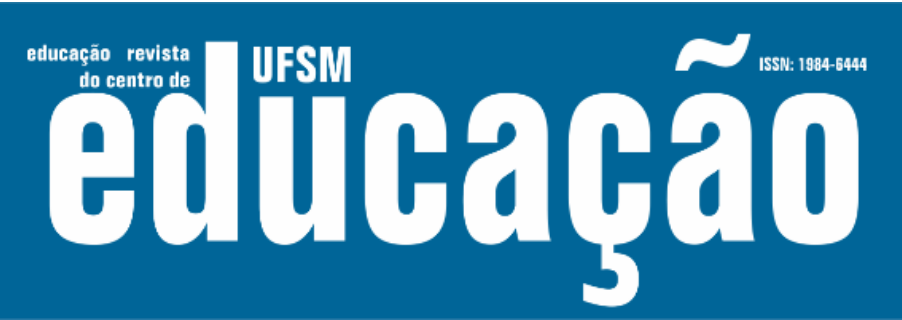

ISSN: 1984-6444 | http://dx.doi.org/10.5902/1984644435603

BARREYRO, Gladys Beatriz; LAGORIA, Silvana Lorena. Acreditação da educação superior na américa latina: os casos da argentina e do brasil no contexto do MERCOSUL. Cadernos PROLAM/USP, São Paulo, v. 9, n. 16. 2010. Disponível em: http://www.revistas.usp.br/prolam/article/view/82391. Acesso em: 02 ago. 2017.

BELLONI, Isaura. Avaliação institucional: um instrumento de democratização da educação. Linhas críticas. Brasília: DF, v. 5, n. 9, p. 31-58, 1999. Disponível em: http://periodicos.unb.br/index.php/linhascriticas/article/view/6711/5418. Acesso em: 04 out. 2018.

BRASIL. Instituto Nacional de Estudos e Pesquisas Educacionais Anísio Teixeira INEP. Comissão Nacional de Avaliação da Educação Superior - CONAES. Roteiro de Auto-Avaliação Institucional, 2004. Brasília: Inep, 2004a. Disponível em: http://portal.inep.gov.br/documents/186968/484109/Roteiro+de+autoavalia\%C3\%A7\%C3\%A3o+institucional+orienta\%C3\%A7\%C3\%B5es+gerais+2004/5 5b435d4-c994-4af8-b73d-11acd4bd4bd0?version=1.2. Acesso em: 06 abr. 2018.

BRASIL. Instituto Nacional de Estudos e Pesquisas Educacionais Anísio Teixeira INEP. Comissão Nacional de Avaliação da Educação Superior - CONAES.

Orientações gerais para o roteiro da auto-avaliação das instituições, 2004b. Brasília: Inep, 2004b. Disponível em:

http://download.inep.gov.br/download/superior/sinaes/orientacoes_sinaes.pdf. Acesso em: 17 nov. 2017.

BRASIL. Lei $n^{\circ} 10.861$, de 14 de abril de 2004a. Institui o Sistema Nacional de Avaliação da Educação Superior - SINAES, e dá outras Providências. Diário Oficial [da] República Federativa do Brasil, Brasília, DF, 15 abr. 2004a. Disponível em: http://www.planalto.gov.br/ccivil_03/_ato2004-2006/2004/lei//10.861.htm. Acesso em: 20 out. 2017.

CHIZZOTTI, Antonio. Pesquisa em ciências humanas e sociais. São Paulo: Cortez, 8르 ed. 2006.

DA SILVA, Assim Leão. Avaliação do ensino superior: a dinâmica de implementação do SINAES nas universidades federais no tocante ao instrumento de avaliação interna - CPA. 2009. 261 f. Dissertação (Mestrado) - Universidade Federal de Pernambuco. CE. Educação.

DAGNINO, Eveline. Construção democrática, neoliberalismo e participação: os dilemas da confluência perversa. Revista Política e Sociedade, Florianópolis - SC, v. 3, n. 5, out. 2004. Disponível em:

https://periodicos.ufsc.br/index.php/politica/article/view/1983. Acesso em: 01 jun. 2018. 


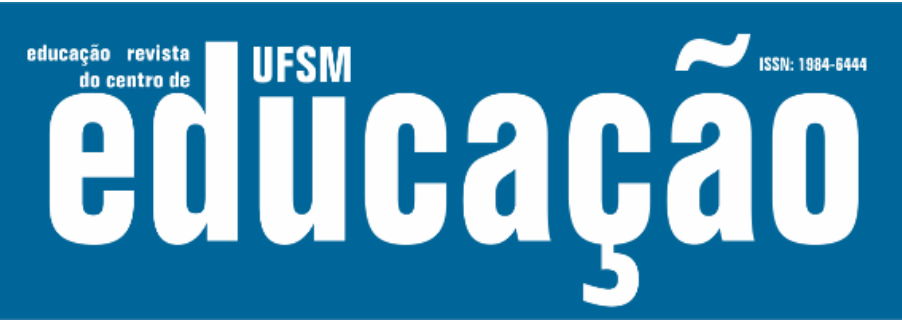

ISSN: 1984-6444 | http://dx.doi.org/10.5902/1984644435603

DIAS SOBRINHO, José. Avaliação como instrumento da formação cidadã e do desenvolvimento da sociedade democrática: por uma ético-epistemologia da avaliação. In: DILVO, R.; ALMEIDA JR., V. P. Avaliação participativa: perspectivas e desafios. Brasília: Inep, 2005. p. 15-38. Disponível em:

http://portal.inep.gov.br/documents/186968/489018/Avalia\%C3\%A7\%C3\%A3o+partic ipativa+perspectivas+e+desafios/65f743ea-cae5-49c3-9248-

d9cb3f170374?version=1.3.Acesso em: 25 abr. 2018.

DIAS SOBRINHO, José. Avaliação ética e política em função da educação como direito público ou como mercadoria? Educação \& Sociedade, Campinas, vol. 25, n. 88, p. 703-725, Especial - Out. 2004. Disponível em:

http://www.scielo.br/pdf/es/v25n88/a04v2588.pdf. Acesso em: 25 abr. 2018.

DIAS SOBRINHO, José. Avaliação institucional: das perspectivas tecnológicas às políticas e sociais. In: DIAS SOBRINHO, José. Avaliação da educação superior. Petrópolis, RJ: Vozes, 2000.

DIAS SOBRINHO, José. Educação superior, globalização e democratização: o debate ético-político. In: LEITE, D. (Org.). Avaliação participativa e qualidade: os atores locais em foco. Porto Alegre: Sulina, 2009. p. 33-56.

EVANGELISTA, Olinda. Apontamentos para o trabalho com documentos de política educacional. In: RONALDO M. L. Araújo; DORIEDSON, S. R. (Org.). A pesquisa em trabalho, educação e políticas educacionais. Campinas-SP: Alínea, 2012, p. 5271.

DIAS SOBRINHO, José; BALZAN, Newton Cesar. (Orgs) Avaliação Institucional: teoria e experiência. 2. Ed. São Paulo: Cortez, 2000.

GIL, Antônio Carlos. Análise e interpretação de dados. 7. ed. São Paulo: Atlas, 2008.

JARDIM, Karolina Da. Silva Miranda. Reforma do Estado e Educação no Brasil e na Argentina nos anos 90. Revista Políticas Educativas, Porto Alegre, v. 4, n. 1, p. 111-116, 2010. Disponível em: http://seer.ufrgs.br/index.php/Poled/article/view/27009. Acesso em: 22 jan. 2018.

KONIG, Erika Himmel. A defesa de uma cultura avaliativa. Cadernos Cenpec, v. 2, n. 3, p. 80-89, 2007. Disponível em:

http://cadernos.cenpec.org.br/cadernos/index.php/cadernos/article/view/2/2. Acesso em: 04 out. 2018. 


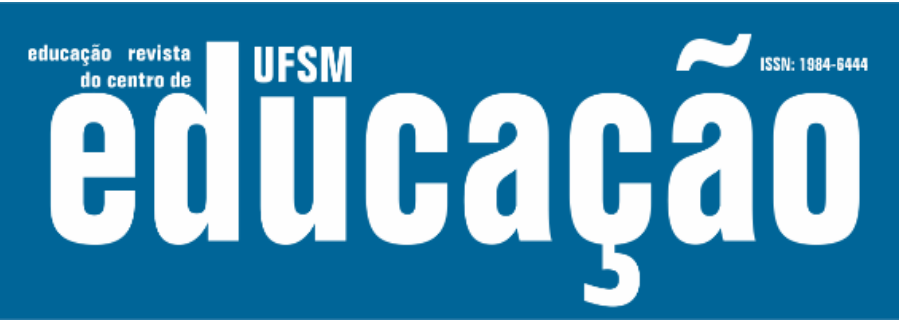

ISSN: 1984-6444 | http://dx.doi.org/10.5902/1984644435603

LAMARRA, Norberto Fernandez. Los sistemas de evaluación y acreditación de la calidad de la educación superior en América Latina: Situación, Problemas y

Perspectivas. Seminário Regional, CONEAU-IESAL/UNESCO, may. 2005.

Disponível em:

http://acfo.edu.co/educacion/pdf/CALIDAD/acr\%20america\%20latina.pdf. Acesso em: 26 jan. 2018.

LAKATOS, Eva Maria; MARCONI, Marina de Andrade. Metodologia científica. 6.ed. rev. e ampl. São Paulo: Atlas, 2011.

LEITE, Denise. Reformas Universitárias. Avaliação Institucional Participativa. Petrópolis: Ed. Vozes, 2005.

MANCEBO, Deise; VALE, Andréa Araújo do; MARTINS, Tânia Babosa. Política de expansão da educação no Brasil 1995-2010. Revista Brasileira de Educação, Rio de Janeiro, v. 20, n. 60, p. 31-50, jan./mar. 2015. Disponível em:

http://www.scielo.br/pdf/rbedu/v20n60/1413-2478-rbedu-20-60-0051.pdf. Acesso em: 23 jan. 2018.

MINAYO, Maria Cristina de Souza. Ciência, técnica e arte: o desafio da pesquisa social. In: MINAYO, Maria Cristina de Souza (Org.). Pesquisa social: teoria, método e criatividade. 3. ed. Petrópolis: Vozes, 1994.

MOLLIS, Marccela. Las reformas de la educación superior en Argentina para el nuevo milenio. Revista da Avaliação da Educação Superior - Avaliação,

Campinas; Sorocaba, v. 13. n. 2. p. 509-532, jun. 2008. Disponível em: http://www.scielo.br/scielo.php?script=sci_arttext\&pid=S1414-40772008000200012. Acesso em: 19 jan. 2018.

MOROSINI, Marilia Costa. (Org.). Universidade no MERCOSUL: condicionantes e desafios. 2. ed. São Paulo: Cortez, 1998.

MOZZATO, A. R.; GRZYBOVSKI, D. Análise de Conteúdo como Técnica de Análise de Dado Qualitativos no Campo da Administração: Potencial e Desafios. RAC, Curitiba, v. 15, n. 4, p. 731-747, jul-ago. 2011. Disponível em: http://www.scielo.br/pdf/rac/v15n4/a10v15n4. Acesso em: 24 abr. 2018.

NOGUEIRA, Marco Aurélio. Um Estado para a Sociedade Civil: temas éticos e políticos da gestão democrática. 3. ed. São Paulo: Cortez, 2011.

PAULA, Ana Paula Paes de. Por uma nova gestão pública: limites e potencialidades da experiência contemporânea. Rio de Janeiro: FGV, 2005. 


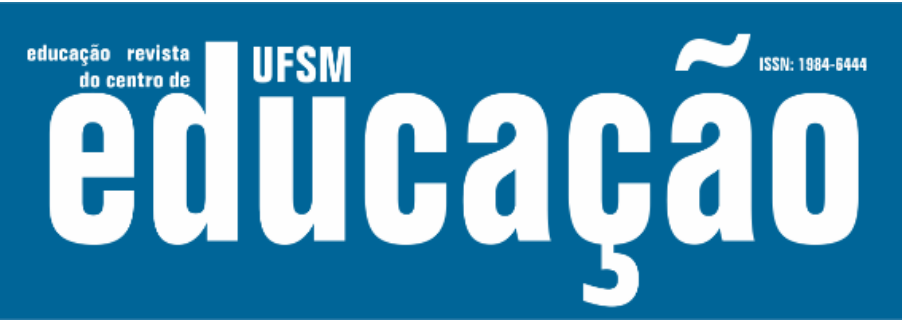

ISSN: 1984-6444 | http://dx.doi.org/10.5902/1984644435603

PARAGUAY. Agencia Nacional de Evaluación y Acreditación de la Educación Superior - ANEAES. Modelo Nacional de Evaluación y Acreditación: mecanismo de evaluación y acreditación institucional. Asunción, 2014. Disponível em: http://www.aneaes.gov.py/aneaes/datos/Mecanismo/01_Mecanismo_de_evaluacion_ institucional.pdf. Acesso em: 07 de abr. 2018.

PARAGUAY. Agencia Nacional de Evaluación y Acreditación de la Educación Superior - ANEAES. Resolución, $n^{\circ}$ 43/2015. Se aprueba la implementación experimental del mecanismo de evaluación y acreditación institucional y sus documentos orientadores, en seis instituciones de educación superior selecionadas, durante los años 2015 y 2016. 2015. Disponível em:

http://www.aneaes.gov.py/aneaes/images/Resolucion_ANEAES_43_15.pdf. Acesso em: 15 mai. 2018.

PASQUARELLI, Bruno Vicente Lippe. Política Comparada: Tradições, Métodos e Estudos de Caso. Revista Agenda Política, São Carlos, v. 2, n.2, 2014, p. 10-38. Disponível em:

http://www.agendapolitica.ufscar.br/index.php/agendapolitica/article/view/39. Acesso em: 24 out. 2017.

PFEIFER, Mariana. Dicotomias conceituais da avaliação da educação superior. Revista da Avaliação da Educação Superior - Avaliação, Campinas; Sorocaba, v. 17, n. 2, p. 351-364, abr. 2012. Disponível em:

http://periodicos.uniso.br/ojs/index.php/avaliacao/article/view/759. Acesso em: 26 abr. 2018.

PINTO, Marli Dias de Souza; HEINZEN, Jadna Lúcia Neves; MELO, Pedro Antonio de Avaliação como compromisso e instrumento de gestão nas instituições de ensino superior. Revista da Avaliação da Educação Superior - Avaliação, Campinas; Sorocaba, v. 10, n. 1, p. 105-119, fev. 2005. Disponível em: http://periodicos.uniso.br/ojs/index.php/avaliacao/article/view/1299. Acesso em: 16 abr. 2018.

POLIDORI, Marlis Morosini; FONSECA, Denise Grosso da; LARROSA, Sara Fernanda Tarter. Avaliação Institucional Participativa. Revista da Avaliação da Educação Superior - Avaliação, Campinas; Sorocaba, v. 12, n. 2, p. 333-348, mai. 2007. Disponível em:

http://periodicos.uniso.br/ojs/index.php/avaliacao/article/view/228. Acesso em 25 abr. 2018.

RISTOFF, Dilvo. Avaliação institucional: pensando princípios. In: DIAS SOBRINHO, José; BALZAN, Newton Cesár. (Org.) Avaliação Institucional: teoria e experiências. 2. Ed. São Paulo: Cortez, 2000. 


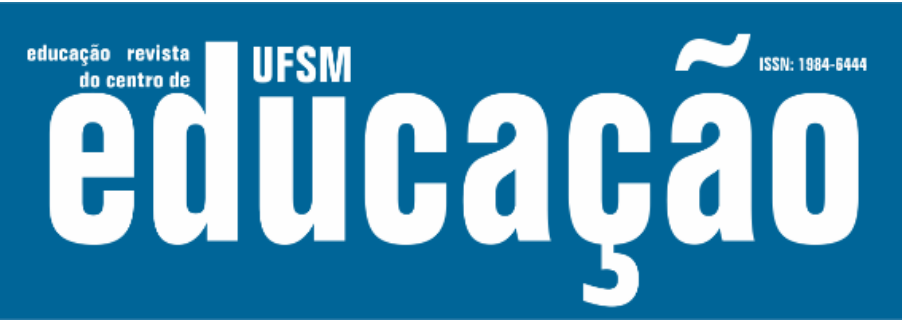

ISSN: 1984-6444 | http://dx.doi.org/10.5902/1984644435603

SANTIAGO, Rui. et al. Modelos de governo, gerencialismo e avaliação institucional nas universidades. Revista Portuguesa de Educação, Braga, Portugal, v. 16, n. 1, p. 75-99, 2003. Disponível em: https://www.researchgate.net/profile/Denise_Leite/publication/26465022_Modelos_d e_governo_gerencialismo_e_avaliacao_institucional_nas_universidades/links/0912f5 08e98cdb392c000000/Modelos-de-governo-gerencialismo-e-avaliacao-institucionalnas-universidades.pdf. Acesso em: 15 mar. 2018.

SANTOS, André Marenco dos. Quando comparamos para explicar: Desenhos de pesquisa e sequências temporais na investigação de instituições políticas. Revista Brasileira de Ciências Sociais - RBCS, São Paulo, v. 27, n. 80, p. 203-217, out. 2012. Disponível em: http://www.scielo.br/pdf/rbcsoc/v27n80/v27n80a12.pdf. Acesso em: 05 set. 2017.

SANTOS, Boaventura de Souza. A universidade no século XXI: para uma reforma democrática e emancipatória da universidade. 3. ed. São Paulo: Cortez, 2011.

SILVA, Assis Leão da. Avaliação do ensino superior: a dinâmica de implementação do SINAES nas universidades federais no tocante ao instrumento de avaliação interna - CPA. 2009. 261 f. Dissertação (Mestrado em Educação) Universidade Federal de Pernambuco, Recife, 2009.

SILVA, Fabiany de Cássia Tavares. Estudos comparados como método de pesquisa: a escrita de uma história curricular por documentos curriculares. Revista Brasileira de Educação, Rio de Janeiro, v. 21, n. 64, p. 209-223, jan.-mar.2016. Disponível em: http://www.scielo.br/pdf/rbedu/v21n64/1413-2478-rbedu-21-640209.pdf. Acesso em: 17 out. 2019.

SILVA JR, João dos Reis.; FERREIRA, Luciana Rodrigues.; KATO, Fabióla Bouth Grello. Trabalho do professor pesquisador diante da expansão da pósgraduação no Brasil pós-LDB. Revista Brasileira de Educação, Rio de Janeiro, v. 18, n. 53, p. 435-499, abr.-jun. 2013. Disponível em:

http://www.scielo.br/pdf/rbedu/v18n53/11.pdf. Acesso em: 20 jan. 2018.

SOUZA FILHO, Rodrigo. Gestão Pública e democracia: a burocracia em questão. Rio de Janeiro: Lumen Juris, 2013.

TEODORO, Antonio; GUILHERME, Manuela. A educação superior em tempos de mudança na América Latina e na Europa: anotações para uma agenda alternativa. Revista Laplage, Sorocaba, v. 3, n. 3, p. 8-16, set.-dez. 2017. Disponível em: http://www.laplageemrevista.ufscar.br/index.php/lpg/article/view/394. Acesso em: 24. Jan. 2018. 


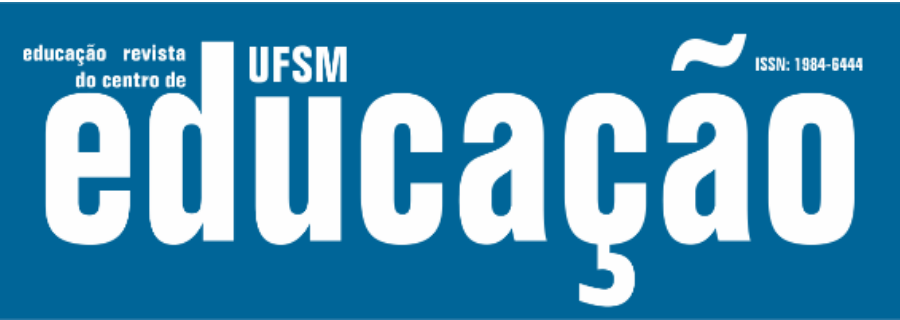

ISSN: 1984-6444 | http://dx.doi.org/10.5902/1984644435603

TELLO, César. Las políticas educativas en Latinoamérica: Derroteros: avances y preocupaciones. (1990-2012). In: ALMEIDA, M. L. P.; CATANI, A. M. (Org.).

Educação Superior Iberoamericana: uma análise para além das perspectivas mercadológicas da produção de conhecimento. Buenos Aires: CLACSO, cap. 1. 2015.

UNIVERSIDAD NACIONAL DEL ESTE. Compendio del Reglamento General. 2016. Disponível em:

http://www.une.edu.py/web/images/pdf/reglamentogral2016.pdf. Acesso em: 20 fev. 2018.

UNIVERSIDAD NACIONAL DEL NORDESTE. Autoevaluación Institucional de la Universidad Nacional del Nordeste 2008. Corrientes, Abril 2008. Disponível em: http://hum.unne.edu.ar/institucional/autoevaluacion_unne.pdf. Acesso em: 15 jun. 2018.

UNIVERSIDADE FEDERAL DA FRONTEIRA SUL. Relatório de autoavaliação institucional: 2017. Chapecó, 2018. 173p. Disponível em:

https://www.uffs.edu.br/pastas-ocultas/bd/gabinete-do-reitor/equipes-detrabalho/comissao-propria-de-avaliacao/autoavaliacao-

institucional/arquivos/relatorio-de-autoavaliacao-institucional-ano-base-2017. Acesso em: 07 abr. 2018.

UNIVERSIDADE FEDERAL DA FRONTEIRA SUL. Resolução n 006/2012 CONSUNI. Homologa o Regimento Interno da Comissão Própria de Avaliação da UFFS. 2012. Disponível em:

https://www.uffs.edu.br/institucional/comissoes/comissao_propria_de_avaliacao/regi mento-interno. Acesso em 04 abr. 2018.

UNIVERSIDADE TECNOLÓGICA FEDERAL DO PARANÁ. Deliberação n 07/2009 - COUNI. Regimento Geral da Universidade Tecnológica Federal do Paraná.

2009. Disponível em: http://www.utfpr.edu.br/a-instituicao/documentos-

institucionais/regimento-geral. Acesso em: 24 jan. 2018.

UNIVERSIDADE TECNOLÓGICA FEDERAL DO PARANÁ. Relatório de

Autoavaliação Institucional da UTFPR: 2016. Curitiba, 2017. 358p. Disponível em: http://www.utfpr.edu.br/estrutura-universitaria/diretorias-de-gestao/diretoria-degestao-da-avaliacao-institucional/cpa-comissao-propria-de-

avaliacao/RelatorioAutoAvalicao2016.pdf/view. Acesso em: 11 abr. 2018. 


\section{$-1$

ISSN: 1984-6444 | http://dx.doi.org/10.5902/1984644435603

VITALE, Claudio Rama. La tercera reforma de la educación superior en América Latina y el Caribe: masificación, regulaciones e internacionalización. Revista

Educación y Pedagogía, Medellín, v. 18, n. 46, p. 11-24, sep.-dic. 2006. Disponível em:

http://aprendeenlinea.udea.edu.co/revistas/index.php/revistaeyp/article/view/6875.

Acesso em: 25 jan. 2018.

\section{Correspondência}

Weslei Trevizan Amâncio - Universidade Tecnológica Federal do Paraná, Avenida dos Pioneiros, 3131, Jardim Morumbi, CEP 86036-370, Londrina, Paraná, Brasil.

\section{Notas}

1 São as universidades participantes do processo experimental: Universidad Nacional de Asúncion; Universidad Nacional del Este; Universidad Católica; Universidad del Cono Sur de las Américas; Universidad Autónoma de Asúncion; Instituto Superior de Educación "Dr. Raúl Peña" (PARAGUAY, 2015).

2 De acordo com Vitale (2006), no desenvolvimento histórico das universidades da América Latina destacam-se três fases de intensos processos reformadores. A primeira no início do século XX, tendo a Reforma da Universidade de Córdoba, em 1918, como marco, com a busca de autonomia e democratização das instâncias e espaços de decisão universitários; a segunda, a partir da década de 1980, marcada pelo processo de mercantilização da oferta universitária, com a diversificação dos seus formatos, restrição da educação pública e liberalização e massivo crescimento das instituições privadas; e a terceira, vivida nos tempos mais recentes, de intensos movimentos de internacionalização das instituições e lógica de funcionamento.

${ }^{3}$ Mais informações sobre o processo de expansão da educação superior podem ser adquiridas no artigo "Organização e expansão da educação superior em tempos neoliberais: os casos da Argentina, Brasil e Paraguai" (AMANCIO; ALVES, 2018). Disponível em: http://www.periodicoseletronicos.ufma.br/index.php/reducacaoemancipacao/article/view/9734

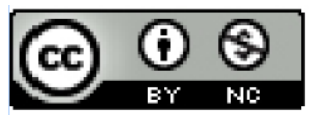

This work is licensed under a Creative Commons Attribution-NonCommercial 4.0 International (CC BY-NC 4.0) 